\title{
Structured approach bags chemistry prize
}

\section{David Adam, London}

Discerning the shape and structure of biomolecules is a sizeable problem - huge, complicated structures such as proteins are among the toughest molecules to analyse. Three researchers who developed key tools to study these giants have been rewarded with the Nobel Prize in Chemistry.

Half of the prize goes to Kurt Wüthrich of the Swiss Federal Institute of Technology in Zürich and the Scripps Research Institute in California, for finding ways to determine the three-dimensional structures of large biological molecules using nuclear magnetic resonance (NMR) spectroscopy

John Fenn of the Virginia Commonwealth University in Richmond and Koichi Tanaka of the Shimadzu Corporation in Kyoto share the other half for inventing techniques to identify and analyse proteins and other large structures using mass spectrometry. At 43, Tanaka is the youngest chemistry laureate since 1967, and the second Japanese scientist to receive a Nobel this year, following physics winner Masatoshi Koshiba.

"The possibility of analysing proteins in detail has led to increased understanding of the processes of life," says the Nobel Foundation. "Researchers can now rapidly and simply reveal what different proteins a sample contains and also determine what protein molecules look like in solution."
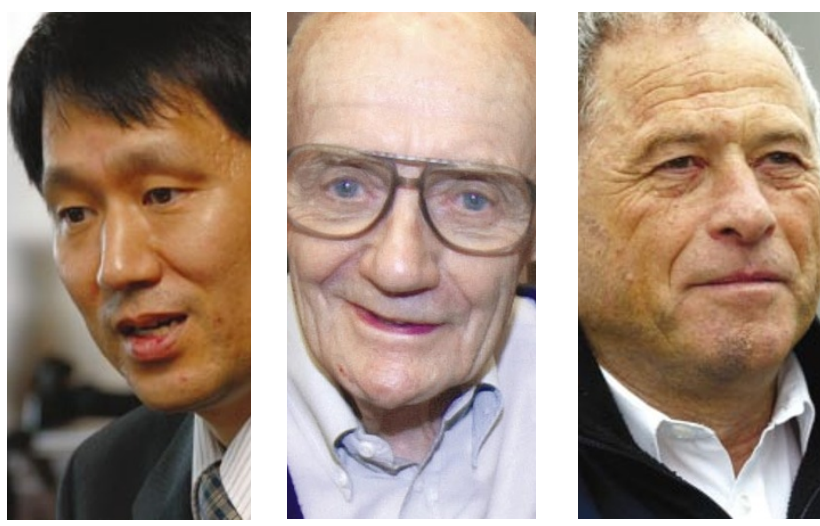

Broad spectrum: techniques devised by (from left) Koichi Tanaka, John Fenn and Kurt Wüthrich have helped to reveal the secrets of protein structure.

Chemists have used NMR and mass spectrometry for decades to study small molecules. But the large size and complex structure of proteins posed problems for biologists wanting to do the same.

NMR analyses the way a molecule's atoms absorb radio waves in a powerful magnetic field. Proteins can contain thousands of atoms, so they give highly confusing NMR spectra. But in the 1980s, Wüthrich showed that NMR is possible for proteins. He invented 'sequential assignment' in which he determined the distance between any two hydrogen atoms in the molecule. He could then pair each peak of radio absorption with a hydrogen nucleus in the protein. This allowed the structure of proteins to be determined in the form in which they exist in the body - in solution rather than as crystals.

Mass spectrometry is a highly sensitive analytical tool that separates molecules according to their size. Fenn and Tanaka found ways of turning proteins into a charged vapour, to be accelerated by an electric field and detected in a mass spectrometer.

Tanaka's technique - soft laser desorption - uses a laser pulse to blast material from solid or viscous biological samples. Fenn developed a different approach, electrospray ionization, which creates a fine spray from a protein solution using an electric field.

Fenn has "been in a total state of shock" since being given the news in a dawn phone call on 9 October. "It's like being struck by lightning," he says. "You know it happens to some people but the odds are so great you never believe it will happen to you."

\section{Economists honoured for experimental angle}

\section{Rory Howlett, London}

Two researchers who put practical ideas to work in a theory-dominated discipline have netted this year's Nobel prize in economics.

Daniel Kahneman of Princeton University in New Jersey integrated psychology into economics, showing how human judgement and decision-making help to shape economic processes. He shares the prize with Vernon Smith of George Mason University in Virginia, who pioneered the use of real experimental data as a check on economic theory.

"Economics textbooks are full of theory, but have no data or experimental results," explains Herbert Gintis of the University of Massachusetts in Amherst. "We need to understand how people actually behave and how this affects economic institutions."

Classical economic theory rests on the idea that people will behave rationally, in their own best interests. Kahneman was among the first to show that people's economic choices are not always rational, however, and can be strongly influenced by their perceptions and emotions. He found

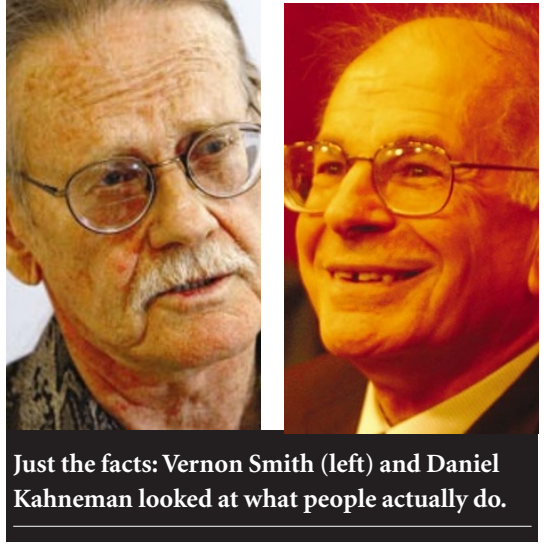

that people often display biases in their economic behaviour that lead to patterns of decision-making that are at odds with what traditional theory predicts.

Having vanquished orthodoxy, Kahneman and the late Amos Tversky proposed a new framework in a classic paper, "Prospect theory: An analysis of decision under risk" (D. Kahneman \& A. Tversky Econometrica 47, 263-291; 1979). Unlike the ideas that it challenges, prospect theory uses empirical observations to generate specific hypotheses that can be tested experimentally.

Smith, meanwhile, has made extensive use of carefully controlled experiments to study how markets behave.

According to economist Samuel Bowles, at the Santa Fe Institute in New Mexico, Smith showed that the standard economic model of how markets work is correct, even as Kahneman proved that the model of rational economic decision-making is wrong. This apparent paradox makes sense, Bowles says, because market models "do not require any particular kind of rationality or high-level cognitive capacity" on the part of participants. He concludes that "the main difference between biological and economic competition - namely, the rationality of the human agents - may be overrated".

Gintis says that Kahneman and Smith's ideas were slow to catch on in academia. But Harvard University, Massachusetts Institute of Technology and the University of Chicago have each now appointed senior faculty in the subdisciplines the duo pioneered. 